\title{
La legitimación en el proceso civil peruano(*)
}

\section{Legitimation in the Peruvian civil process}

\author{
Rafael Prado Bringas( $\left.{ }^{* *}\right)$ \\ Universidad de Lima
}

\section{Orestes Francisco Zegarra Valencia( $\left.{ }^{* * *}\right)$ \\ Rodríguez Angobaldo Abogados}

\begin{abstract}
Resumen: El presente artículo tiene por objetivo definir la legitimación del proceso, así como entender las diferentes clases de legitimación que han sido definidas en la doctrina y, en consecuencia, adoptadas en el proceso civil peruano. Asimismo, busca analizar cómo debe ser el control de este presupuesto en el proceso. No pretende zanjar una controversia, sino únicamente exponer nuestras ideas, e intentar darle a este presupuesto procesal un fin práctico, desde una lectura del mismo a partir de la Constitución y la teoría general del proceso.
\end{abstract}

Palabras Claves: Legitimación - proceso civil peruano - presupuesto procesal - Constitución - civil - procesal.

\begin{abstract}
The objective of this article is to define the legitimacy of the process, as well as to understand the different types of legitimation that have been defined in the doctrine and, consequently, adopted in the Peruvian civil process. Also, it seeks to analyze how the control of this budget should be in the process. It does not intend to settle a controversy, but only to expose our ideas, and try to give this procedural budget a practical purpose, from a reading of it from the Constitution and the general theory of the process.
\end{abstract}

Keywords: Legitimation - Peruvian civil process - procedural budget Constitution - civil - process.

(*) Nota del Editor: Este artículo fue recibido el 10 de noviembre de 2017 y su publicación fue aprobada el 20 de junio de 2018.

${ }^{* *}$ Abogado por la Pontificia Universidad Católica del Perú. Profesor de Derecho Procesal Civil en la Universidad de Lima y de la Universidad Peruana de Ciencias Aplicadas - UPC. Correo electrónico: JPRADOB@ulima.edu.pe

$\left.{ }^{(* *}\right)$ Abogado por la Pontificia Universidad Católica del Perú, con título de Segunda Especialidad en Derecho Procesal otorgado por la Pontificia Universidad Católica del Perú. Con estudios de Maestría de Derecho Procesal en la Pontificia Universidad Católica del Perú. Miembro extraordinario de IUS ET VERITAS. Asociado del Estudio Rodríguez Angobaldo. Correo electrónico: francisco.zegarra@pucp.pe 
Sumario: 1. Introducción_2. La legitimación como presupuesto procesal_3.Fundamento constitucional de la legitimación_4. Diferencia entre la legitimación con otros elementos procesales _5. La legitimación y su clasificación_5.1. La legitimación ordinária _5.1.1. La legitimación ordinaria de derechos individuales y plurales _5.1.2. La legitimación ordinaria de situaciones jurídicas_5.1.3. La legitimación ordinaria de intereses legítimos_5.2. La legitimación extraordinaria_5.2.1. La legitimación extraordinaria de derechos individuales_5.2.2. La legitimación extraordinaria de derechos o intereses supraindividuales_5.2.3. La legitimación extraordinaria de intereses públicos_6. Control de la legitimación en el proceso_ 6.1. El principio de preclusión procesal y el saneamiento de proceso_6.2. Análisis y delimitación del control de la validez de la relación jurídica procesal durante el proceso_6.3. Control de la legitimación durante el proceso_7. Conclusión_8. Referencias bibliográficas

\section{Introducción}

La legitimación como requisito de validez de la relación jurídica procesal ${ }^{(1)}$ constituye uno de los elementos menos estudiados del proceso. Lo anterior ha originado que a menudo se confunda este elemento con otros, tales como la capacidad para ser parte del proceso, la representación procesal, la posibilidad jurídica o física de que la demanda sea amparada; y en el peor de los casos, con el tema de fondo del proceso.

En ese sentido, en nuestro proceso civil la legitimación se utiliza a menudo como una herramienta que permite a los jueces inhibirse de revisar el fondo de la controversia. Con lo anterior no queremos decir que los jueces no puedan emitir sentencias inhibitorias o sanear el proceso en la etapa respectiva, sino que en la práctica el control de la legitimación esconde un análisis distinto al que corresponde, originándose con ello que se distorsione el debido proceso.

En razón a ello, el presente artículo tiene como objetivo intentar definir desde un punto de vista práctico la legitimación en el proceso, así como entender las diferentes clases de legitimación que han sido definidas en la doctrina y a su vez recogidas en el proceso civil peruano. Con este punto de partida, nuestro propósito es analizar cómo debe ser su control dentro del proceso. Todo ello sin olvidar que, como sostendremos más adelante, la legitimación constituye un elemento delimitador del derecho a la tutela jurisdiccional efectiva, por lo que la interpretación de las normas que lo regulan debe realizarse para favorecer la continuación del proceso.

Asimismo, debemos advertir al lector que lo que expondremos a continuación no tiene como objetivo zanjar una controversia sobre la definición y utilidad de un presupuesto procesal tan controvertido como lo constituye la legitimación ${ }^{(2)}$, sino únicamente exponer nuestras ideas, e intentar darle a este presupuesto procesal un fin práctico, desde una lectura del mismo a partir de la Constitución y la teoría general del proceso, y que de esta manera pueda servir como referente a todos los sujetos que intervienen en el proceso.

Finalmente, debemos reconocer que buena parte de las ideas que presentaremos a continuación han sido fruto de lo desarrollado en España por el profesor Juan Montero Aroca, por lo que gran parte de nuestro aporte se limitará a intentar entender cómo debe ser aplicado este concepto en el proceso civil peruano.

\section{La legitimación como presupuesto procesal}

La legitimación constituye uno de los elementos más novedosos del proceso, cuyo origen se

(1) A nivel nacional se conoce que los presupuestos procesales son los requisitos necesarios para la existencia de una relación jurídica procesal válida, los cuales pueden ser formales o materiales (Monroy 1994, 379). Para efectos del presente artículo nos limitaremos a señalar que la relación jurídica procesal debe de cumplir con determinados requisitos de validez (presupuestos procesales), sin hacer distinción en si estos requisitos son formales o materiales.

(2) A propósito, tenemos que un sector de la doctrina señala que la legitimación pertenece al ámbito del derecho material; y por tanto, constituye un asunto de fondo, por lo que el concepto de legitimación queda vacío de contenido. (Nieva Fenoll, 2015, 46). 


\section{Rafael Prado Bringas Orestes Francisco Zegarra Valencia}

remonta al nacimiento de la teoría dualista de la acción, y de la teoría de la relación jurídica procesal.

Recordemos que, de manera previa a esas teorías, se entendía que no existía diferenciación entre el derecho de acción y el derecho subjetivo (teoría monista de la acción), y en ese sentido no cabía individualizar la legitimación como un concepto autónomo, porque el demandante -desde esta perspectiva- siempre era el titular del derecho subjetivo.

En ese sentido la teoría dualista de la acción, iniciada por Muther a raíz de la polémica que sostuvo con Windscheid en los años 1856 y 1867 , propone que el derecho de acción era independiente al derecho material. Mientras el primero se dirige contra el Estado y tiene naturaleza pública, el segundo se dirige contra un particular y su naturaleza es privada; marcando con ello, la existencia de una diferenciación clara entre ambos conceptos.

En esa misma línea, la teoría de la relación jurídica procesal propuesta por Oscar Von Bülow en 1868, puso en manifiesto que el proceso consistía en una relación jurídica pública, y que se debía de cumplir con determinados presupuestos para la emisión de una sentencia de fondo (presupuestos procesales). En aquella oportunidad señaló que "si el proceso es, por lo tanto, una relación jurídica, se presentan en la ciencia procesal análogos problemas a los que surgieron y fueron resueltos, tiempos antes, respecto de las demás relaciones jurídicas. La exposición sobre una relación jurídica debe dar, ante todo, una respuesta a la cuestión relacionada con los requisitos a los que se sujeta el nacimiento de aquella" (Von Bülow 1869, 26). Precisamente uno de los presupuestos procesales es la legitimación.

A partir de este momento se evidencia la necesidad - y utilidad - de definir el concepto de legitimación. Y es que en base a ambas teorías ya no queda claro que se pueda señalar que el titular del derecho subjetivo sea quien pueda dar inicio a un proceso.

En efecto, a partir de la teoría dualista de la acción se entiende que el derecho de acción es independiente al derecho subjetivo, mientras que a partir de la teoría de la relación jurídica procesal se entiende que el sujeto de la relación jurídico material (parte material) y de la relación jurídico procesal (parte procesal) pueden ser distintos, y sólo podrá obtenerse una sentencia de fondo mientras se cumplan con los requisitos establecidos en el proceso para ello (presupuestos procesales).
En conclusión, a partir del concepto de legitimación podemos entender quién puede acudir al proceso y acceder a una sentencia de fondo (entendida esta como una sentencia estimatoria o desestimatoria, claro está).

\section{Fundamento constitucional de la legitimación}

Actualmente no existe controversia en entender que el derecho a la tutela jurisdiccional efectiva constituye un derecho fundamental. En ese sentido, el inciso 1 del artículo 8 de la Convención Americana de Derechos Humanos señala que: "Toda persona tiene derecho a ser oída, con las debidas garantías y dentro de un plazo razonable, por un juez o tribunal competente, independiente e imparcial, establecido con anterioridad por la ley, en la sustanciación de cualquier acusación penal formulada contra ella, o para determinación de sus derechos y obligaciones en orden civil, laboral, fiscal o de cualquier otro carácter".

Asimismo, a nivel nacional, el inciso 3 del artículo 139 de la Constitución establece que constituye un principio y derecho de la función jurisdiccional "la observancia del debido proceso y la tutela jurisdiccional efectiva", y el artículo I del Título Preliminar del Código Procesal Civil señala que: "toda persona tiene derecho a la tutela jurisdiccional efectiva para el ejercicio o defensa de sus derechos o intereses, con sujeción a un debido proceso".

Sobre el particular, el Tribunal Constitucional peruano ha señalado que el derecho a la tutela jurisdiccional efectiva "implica que cuando una persona pretenda la defensa de sus derechos o de sus intereses legítimos, ella deba ser atendida por un órgano jurisdiccional mediante un proceso dotado de garantías mínimas" (STC 0005-2006-Al). 
Ahora bien, con relación al contenido esencial del derecho a la tutela jurisdiccional efectiva, este comprende, entre otros, dos elementos esenciales: (i) el derecho al acceso a la jurisdicción; y, (ii) el derecho a la ejecución de las sentencias judiciales. Sobre el primero de estos, que es el que nos ocupa en el presente artículo, ha señalado: "El derecho a la tutela judicial efectiva es un derecho de contenido complejo que persigue garantizar la eficacia de las situaciones jurídicas, posibilitando a las personas -entre otros-el libre e igualitario acceso a la jurisdicción para la tutela de sus derechos y, de esta forma, se debe eliminar todas las barreras que limiten, restrinjan o impidan este acceso libre e igualitario a los órganos jurisdiccionales" (STC 3072-2006-PA).

Lo establecido en los tratados internacionales, en la Constitución, en el Código Procesal Civil y lo señalado por el Tribunal Constitucional, nos permite afirmar que el derecho al acceso a la jurisdicción constituye un elemento esencial del derecho a la tutela jurisdiccional efectiva. Asimismo, nos permite abordar el presupuesto procesal de la legitimación, ya que, a raíz de ello, podemos afirmar que, por regla general, nadie puede iniciar un proceso en base a cualquier derecho o interés; sino que debe de realizarlo en base a los derechos e intereses que considere propios. A su vez, nos permite afirmar que la demanda debe ser interpuesta contra la persona sobre la cual se considere que recae la imputación de la obligación alegada.

En ese sentido, al constituir la legitimación un presupuesto procesal que delimita el derecho a la tutela jurisdiccional efectiva, su configuración a nivel positivo, así como su aplicación, deben ser realizadas de manera restrictiva y razonable. En palabras del Tribunal Constitucional: "Cualquier impedimento o mecanismo que dificulte su acceso, se convierte en un obstáculo contrario al derecho constitucional de toda persona de acceder sin condicionamientos a la tutela jurisdiccional" (STC 3741-2004-AA). De lo anterior, podemos diferenciar dos mandatos constitucionales, uno dirigido al legislador, y el otro a los jueces.

En primer lugar, constituye un mandato constitucional para el legislador, quien tiene el deber de utilizar "técnicas procesales capaces de atender el derecho material" (Marinoni 2007, 177) al momento de regular la legitimación a través de normas procesales. Así, cuando se trata de derechos inherentes de determinados sujetos, tiene el deber constitucional de permitir que toda persona pueda solicitar la tutela de los derechos que considere propios, contra la persona que considere obligado. Mientras que cuando se trata de derechos o intereses supraindividuales tiene el deber de regular la legitimación de manera que permita una tutela idónea de esta clase de derechos.

En segundo lugar, constituye un mandato constitucional para los jueces, quienes tienen el deber de aplicar las normas que regulan la legitimación de manera restrictiva; invocando una interpretación que permita el favorecimiento del proceso. En palabras del Tribunal Constitucional: "Las limitaciones a los derechos fundamentales sólo pueden establecerse respetando el principio de legalidad, la interpretación de una limitación legalmente interpuesta, deberá, además, realizarse en términos necesariamente restrictivos, encontrándose vedada la interpretación analógica, in malam parten, de las normas que restrinjan derechos" (STC 22352004-PA).

Inclusive, podemos afirmar que existe el deber de aplicar control difuso a aquellas normas que regulan la legitimación e impliquen una limitación irrazonable al derecho a la tutela jurisdiccional efectiva. Ello, sin embargo, no implica una regla, sino la excepción, y todo análisis constitucional de las normas procesales que regulan la legitimación debe presumir la constitucionalidad de las mismas; y corresponde al juez analizar en cada caso concreto, mediante una resolución debidamente motivada, que no existe razonabilidad, proporcionalidad, ni causa objetiva en la delimitación de la legitimación realizada.

\section{Diferencia entre la legitimación con otros elementos procesales}

Habiendo quedado establecido que la legitimación es un presupuesto procesal independiente, la delimitación que realicemos de la misma debe implicar un contenido 


\section{Rafael Prado Bringas Orestes Francisco Zegarra Valencia}

distinto a los otros elementos procesales. En ese sentido, antes de definir de manera exacta lo que constituye la legitimación, partiremos definiendo lo que no es.

Para empezar, la legitimación no puede ser confundida con la capacidad para ser parte de un proceso de manera abstracta, toda vez que la legitimación constituye la capacidad para ser parte del proceso de manera concreta; en ese sentido, la legitimación se refiere a la capacidad que tiene un sujeto de derecho de ser parte en un proceso determinado. La legitimación debe analizarse de manera particular en cada proceso, con relación al demandante y demandado; así como en relación al derecho o intereses que se afirme en la demanda.

Cuando se habla de la capacidad para ser parte en abstracto del proceso, se puede hacer referencia a dos escenarios: (i) capacidad para ser parte en el proceso; y, (ii) capacidad para ser parte procesal. Así tenemos entonces que la capacidad para ser parte se refiere "a la aptitud para ser titular de derechos, cargas y obligaciones que se derivan de la realidad jurídica que es el proceso" (Calamandrei 1989, 297), mientras que la capacidad para ser parte procesal (capacidad procesal) en cambio, es la "aptitud para realizar activa o pasivamente actos jurídicos procesales con eficacia, en nombre propio, que poseen las personas que tiene el libre ejercicio de los derechos que en el proceso se hacen valer" (Matheus 2001, 39).

Además, no se puede confundir legitimación con representación. Esta última institución "posibilita que la parte material actúe en un proceso a través de la actividad procesal realizada por otra persona a su nombre" (Monroy 1995, 276); y puede ser voluntaria, necesaria o legal.

La representación voluntaria "tiene lugar cuando las partes, mediante un poder o un mandato nombran a un representante para que actúe por ellos en el proceso" (Pallares 1979, 139). La representación necesaria se presenta cuando determinada persona tiene capacidad para ser parte del proceso, pero no puede manifestar su voluntad por sí misma, requiriendo participar en el proceso a través de una determinada persona. El caso típico de la representación necesaria lo constituyen las personas jurídicas, quienes "no pueden plantear problemas de incapacidad; la capacidad procesal la tienen desde su constitución. Esto no impide que, en caso determinados, se trate de capacidad limitada que necesita ser integrada, por ejemplo, mediante autorización (...) Lo que hay que preguntarse es qué órgano se atribuye la representación en juicio de todas y cada una de las muchas clases de personas jurídicas. Esta pregunta no puede tener aquí una respuesta concreta porque ella exigirá aludir a afinidad de disposiciones legales, las cuales en buena parte de los casos se limitan a remitirnos a los estatutos de cada ente" (Montero 2007, 65).

La representación legal se refiere a aquellos casos en los cuales la ley impone que determinadas personas actúen a favor de los derechos de otros en el proceso, ya sea porque estos no tienen capacidad para ser parte procesal (por ejemplo, el caso de los menores de edad); o porque por diferentes circunstancias se requiere que se presente una persona a favor de los derechos e intereses de los otros (por ejemplo, en los casos en los que no se puede ubicar al demandado y se le designa curador procesal).

En base a lo anterior, al momento de analizar la legitimación de una parte en el proceso no se puede confundir la misma con la representación de una persona en el proceso. Así, por ejemplo, cuando una madre interpone demanda de alimentos a favor de su hijo, la madre se encuentra actuando en representación de su hijo a efectos de requerir una determinada tutela a favor de este. $\mathrm{O}$ en el caso que un demandante interpone una demanda afirmando que una persona jurídica le ha causado daño, deberá ser interpuesta en contra de la persona jurídica; más no contra el representante legal.

Tampoco puede confundirse la legitimación con la imposibilidad jurídica o física de que la pretensión pueda ser amparada. Así, por ejemplo, en caso que se interponga una demanda de obligación de dar suma de dinero amparada en una obligación originada por juegos de azar, esta persona no es que no 
tenga legitimación para interponer la demanda, sino que está pretensión no podrá ser estimada porque el ordenamiento jurídico no protege ese derecho.

Finalmente, conviene señalar que no se puede confundir legitimación con el asunto de fondo del proceso. Como hemos señalado, la legitimación constituye un presupuesto para la emisión de una sentencia de fondo, por lo que debe de existir una clara diferenciación entre lo que es uno y el otro. Así, una sentencia de fondo implica un pronunciamiento judicial mediante el cual se estima o desestima una determinada pretensión; es decir, se señala si existe o no el derecho o interés invocado por el demandante y si el demandado es el sujeto sobre el cual recae la titularidad de la obligación afirmada.

A decir de Montero Aroca "Con la legitimación se trata de determinar quién debe estar en el proceso para que el juez pueda proceder al examen de fondo, de modo que su naturaleza y función es procesal. Si la titularidad de la relación jurídica material determina el contenido de la sentencia, la legitimación fundamenta el desarrollo del proceso y su problemática se localiza en un momento anterior, el de la admisibilidad de la demanda" (Montero 2007, 75). En esa misma línea, Giovanni Priori señala: "Se trata solamente de declarar; es decir, de afirmar la titularidad de las situaciones jurídicas controvertidas. Estas afirmaciones son las que constituyen la posición habilitante de la legitimidad para obrar" (Priori 2010, 66).

Así, en el caso del demandante, cualquier cuestión relacionada con la titularidad y acreditación del derecho invocado constituye una cuestión de fondo, que debe ser resuelta mediante una sentencia estimatoria o desestimatoria. Mientras que, en el caso del demandado, cualquier cuestión relacionada a la titularidad de la obligación que se afirme que recae en su persona; así como la acreditación de los hechos impeditivos o extintivos en los que sustente su defensa, ameritará un pronunciamiento de fondo. En ningún caso se podrá emitir cualquier tipo de pronunciamiento inhibitorio amparándose en falta de legitimación en los supuestos anteriormente señalados.

\section{La legitimación y su clasificación}

Entonces, la legitimación constituye la afirmación de la titularidad que debe realizar el demandante sobre el derecho o interés invocado, y la imputación de la obligación que debe realizar del mismo hacia el demandado. Así, la legitimación como presupuesto procesal se debe limitar a controlar que, como regla general, la persona que interponga la demanda sea la que afirme ser la titular del derecho, mientras que la persona contra la que se interponga la demanda, sea sobre la cual recae la imputación de la obligación.

Como hemos visto, la legitimación constituye un elemento delimitador del derecho a la tutela jurisdiccional efectiva (específicamente del derecho de acceso a la jurisdicción) y de acuerdo al marco constitucional que tenemos, los procesos deben ser iniciados por las personas que se consideren ser titulares de los derechos que se discuten. Inclusive, el marco del proceso civil moderno responde a este esquema, toda vez que el proceso se rige a partir del principio dispositivo, con lo cual se reconoce que sólo los que se consideren titulares derechos pueden iniciar un proceso.

Ahora bien, el concepto de legitimación no es estático, sino que obedece a la efectivización de la tutela de derechos que se invoca en el proceso. De ahí que, si bien el esquema tradicional de legitimación ha sido entendido en el marco de un conflicto entre dos individuos sobre derechos individuales, la legitimación, como presupuesto procesal, se ha visto obligada a responder a más.

En ese orden de ideas es que la legitimación ha sido dividida en dos categorías: (i) la legitimación ordinaria; y, (ii) la legitimación extraordinaria.

A su vez, y como desarrollaremos a continuación, ambas clases de legitimación han sido delimitadas con determinadas características con el objetivo de responder de manera más idónea a las necesidades del proceso y los derechos en conflicto. En ese 


\section{Rafael Prado Bringas Orestes Francisco Zegarra Valencia}

sentido, veremos cómo es que, por ejemplo, la legitimación individual dio paso a la legitimación plural; la acumulación de intereses individuales (conflicto plural) evolucionó para dar paso a la protección de intereses individuales homogéneos: y, finalmente, la protección de derechos individuales ha dado paso a la protección de derechos o intereses supraindividuales.

\subsection{La legitimación ordinaria}

La legitimación ordinaria constituye la regla general de legitimación y la misma obedece al esquema tradicional del proceso: la de una persona solicitando la protección de sus derechos frente a otra.

Sin embargo, el esquema tradicional de la legitimación es mucho más amplio de lo que a primera impresión pareciera ser. Por ejemplo, existen casos en los cuales la afirmación de la titularidad del derecho debe ser invocada por más de una persona, sin que ello implique encontrarnos ante más de una parte; o, hay casos en los cuales se invoca la afirmación de titularidad de situaciones jurídicas o de intereses legítimos.

A continuación, procederemos a desarrollar cada uno de los supuestos en los cuales se invoca la legitimación ordinaria en el proceso.

5.1.1. La legitimación ordinaria de derechos individuales y plurales

La legitimación ordinaria implica que el demandante debe afirmar ser titular del derecho cuya tutela requiere y el demandado debe ser el sujeto a quien se le imputa la obligación. Señala Montero Aroca: "La legitimación ordinaria se resuelve de esta manera, ahora ya disponerlo así una norma de modo expreso, en unas simples afirmaciones, que pueden examinarse desde dos perspectivas: 1) Activa: afirmación de titularidad del derecho subjetivo, y, 2) Pasiva: afirmación de titularidad de la obligación. Si el derecho subjetivo existe y si la obligación correlativa existe, incluyendo tanto el aspecto objetivo (existe la relación jurídica) como el subjetivo (son efectivamente titulares de la misma el actor y el demandado), sólo podrá saberse al final del proceso, pero inicialmente éste solo tendrá sentido, sólo podrá desarrollarse válidamente, si el que lo insta afirma ser titular del derecho e imputa la titularidad de la obligación a la persona que demanda" (Montero 2007, 154).

Lo anterior constituye la regla general de la legitimación ordinaria, que es a la cual la mayoría de las normas procesales se limitan a hacer referencia. Así, por ejemplo, cuando una norma señala que el propietario está legitimado para demandar la reivindicación de un bien de su propiedad, no hace más que afirmar la regla general de la legitimación: quien se considere propietario de un determinado bien puede demandar su reivindicación.

En estos casos, las normas que regulan la legitimidad se limitan a invocar que el titular de un determinado derecho tiene legitimación; sin embargo, como hemos visto, precisamente se trata de invocar la afirmación de la titularidad aquel derecho, y no sobre cualquier derecho, sino sobre aquel que da origen al conflicto. En el caso citado, quien desea demandar la reivindicación de un determinado bien debe de afirmar ser el titular del derecho de propiedad del bien materia de conflicto.

Ahora bien, si lo común es que la afirmación de la titularidad del derecho la realice una persona, y que la imputación de la obligación recaiga sobre otra, existen situaciones en las cuales, por la naturaleza del derecho que se discute, la afirmación de la titularidad, o la imputación de la obligación recaen sobre una pluralidad de sujetos. Estos casos son los que constituyen los supuestos de legitimación plural, más comúnmente conocidos como litisconsorcio necesario.

El litisconsorcio necesario se "desprende de la naturaleza de la relación jurídicomaterial respecto de la que (las partes) hacen las afirmaciones legitimadoras" (Montero 2007, 223). En tal sentido, existirá litisconsorcio necesario en los supuestos que es "necesario para que pueda concluirse que existe legitimación que la afirmación activa la hagan todos los titulares del derecho y/o que la imputación pasiva se haga frente a todos los titulares de la obligación" (Montero, 221).

5.1.2. La legitimación ordinaria de situaciones jurídicas

En los casos de tutela de situaciones jurídicas, la norma procesal establece quienes son los 
que deben requerir la tutela. Al respecto, se ha señalado que "en estos casos la situación es diferente respecto de la legitimación, pues normalmente es la propia que determina caso por caso quienes están legitimados para pedir la modificación de la situación jurídica" (Montero 2007, 173).

En estos casos, no existe una limitación de la legitimación, sino una decisión discrecional y válida por parte del legislador en determinar quién tiene legitimación. Conforme señala Montero Aroca: "Unas veces se trata de que la legisladora concreta quienes pueden pedir la actuación de la ley en un caso concreto y lo hace en atención a relaciones y situaciones jurídicas muy variadas. Se trata aquí de decisiones legislativas basadas en la discrecionalidad política. Respecto de ellas no puede afirmarse que la legitimación radique en posición habilitante alguna, pues consiste en estar a lo dispuesto en la ley. Tiene legitimación quien la ley lo determina, y nada más, sin que se entre a considerar la situación o posición del legitimado respecto de la relación jurídica material o de una situación jurídica" (Montero 2007, 183).

Así, por ejemplo, en los casos de nombramiento de curador por desaparición, el Código Civil establece que determinadas personas (cualquier familiar hasta el cuarto grado de consanguinidad o afinidad) están legitimadas a solicitar la designación de un curador interino.

\subsubsection{La legitimación ordinaria de intereses legítimos}

Finalmente, si bien es cierto lo general es que las afirmaciones de titularidad recaigan sobre derechos, el ordenamiento jurídico también protege los intereses legítimos. En ese sentido, existen casos en los que la norma procesal dispondrá aquellos supuestos en los que los intereses legítimos se protegen.

Los intereses legítimos cuya tutela se protegen implican situaciones de ventaja o de utilidad jurídica por el ejercicio de determinada pretensión. Así, a diferencia de los casos en los que existe legitimación de situaciones jurídicas independientes, en el caso de la legitimación de intereses legítimos nos encontramos ante un supuesto que se asemeja más a la regla general, ya que el demandante no requiere la actuación de la ley en un caso concreto, sino, que lo hace a partir de una situación de ventaja que el ordenamiento jurídico le reconoce a su favor.

En ese contexto, la legitimación por intereses legítimos "responde necesariamente a la afirmación de titularidad de una relación o situación jurídica que se tiene respecto de otra relación jurídica o situación jurídica de un o unos terceros, de modo que, si bien no se trata de sujetar a esos terceros a prestaciones de hacer, no hacer o dar, sí debe tratarse de que: 1) Negativamente, por medio de esta legitimación una persona pretende evitar el perjuicio que le podría ocasionar, en su relación o situación jurídica la realización de una actividad por otra persona, (...) 2) Positivamente, de la misma manera, se trataría de una persona puede obtener un beneficio por medio de la tutela judicial de su interés, beneficio que no tiene que ser necesariamente económico, aunque lo sea normalmente. El interés es entonces la ventaja o titularidad que se obtendría en caso de prosperar la pretensión ejercitada en el proceso, y su existencia viene determinada por la efectividad de esa utilidad" (Montero 2007, 204).

El supuesto clásico de legitimación por intereses legítimos lo constituye el caso de nulidad de acto jurídico pretendido por terceros que no han sido parte del mismo, toda vez que la norma civil se limita a señalar que la nulidad puede ser alegada por quienes tengan interés. En dicho contexto, y como generalmente lo han establecido los tribunales, tienen legitimidad para interponer la demanda los terceros ajenos al acto jurídico que pueden ver sus derechos burlados o menoscabados con la relación contractual.

Por último, la legitimación por intereses legítimos "no podrá tratarse obviamente de la exigencia por el tercero de que por otras personas se respete el derecho objetivo, en general, pues no puede existir una acción popular civil, pero sí de que no realicen esas otras personas actuación alguna que le suponga un perjuicio que no tenga que soportar al venirle impuesto por la ley. De ahí que la exigencia de que el interés legítimo tiene que ser personal, en el sentido de que se diferencia del mero interés general" (Montero 2007, 205). 


\section{Rafael Prado Bringas Orestes Francisco Zegarra Valencia}

\subsection{La legitimación extraordinaria}

La legitimación extraordinaria se refiere a todos aquellos supuestos en los que se permite a una persona iniciar una demanda sin afirmar la titularidad del derecho invocado. Esta clase de legitimación constituye un supuesto de excepción; ya que, en principio, el ordenamiento constitucional y, la naturaleza del proceso civil, permiten que sea sólo el que afirme la titularidad del derecho quien interponga la demanda.

La excepcionalidad que caracteriza esta clase de legitimación implica que sólo se permitirá cuando exista una norma habilitante expresa. Asimismo, esta norma quedará sujeta a un control de constitucionalidad, y la validez de la misma dependerá del grado de delimitación del derecho al acceso a la jurisdicción que represente, y los fines que persigue tutelar.

La razón por la que se permite esta clase de legitimación es sencilla: el proceso debe ser dúctil y adaptarse a las necesidades de los derechos materiales para así lograr una adecuada tutela jurisdiccional efectiva. En palabras de Marinoni: "Como el derecho a la efectividad de la tutela jurisdiccional debe atender al derecho material, es natural concluir que el derecho a la efectividad engloba el derecho a la preordenación de técnicas procesales capaces de dar respuestas adecuadas a las necesidades que de él provienen" (Marinoni 2007, 176).

En ese contexto, la idónea defensa de derechos e intereses individuales, supraindividuales y públicos han generado que en determinadas circunstancias se utilice la legitimación extraordinaria para: (i) limitar la legitimación de la persona a la que le corresponde realizar la afirmación de la titularidad del derecho y otorgársela a otra; o, (ii) ampliar la legitimación de las personas que pueden iniciar una demanda, adhiriendo a otras que no afirman la titularidad del derecho invocado.

En ese sentido, y en base a la clase de derechos e intereses a los que hemos hecho referencia (individuales, supraindividuales y públicos), desarrollaremos los supuestos en los que se utiliza la legitimación extraordinaria para limitar o ampliar los supuestos de legitimación.

Finalmente, conviene señalar que en los casos en los que el ordenamiento jurídico le asigna la titularidad de un derecho a una persona que, en principio, le pertenecía a otra, no nos encontraríamos ante un supuesto de legitimación extraordinaria, sino ante una suerte de "cesión legal de derechos". Y es que a la legitimación extraordinaria solamente le conciernen los casos en los que se le permite a una persona interponer una pretensión sin afirmar la titularidad del derecho invocado. La diferencia radica en que en el caso de la "cesión legal de derechos" la persona que interpondría la pretensión lo estaría haciendo en base a la afirmación de un derecho que considera suyo.

\subsubsection{La legitimación extraordinaria de} derechos individuales

En principio, la defensa de derechos e intereses individuales pertenece a la persona que afirma la titularidad; sin embargo, por circunstancias excepcionales, se permite que sea un tercero el que requiera tutela jurisdiccional efectiva a favor del titular del derecho.

Estas circunstancias excepcionales suelen justificarse en la falta de otros medios para la tutela de los derechos que se invocan. Esta clase de legitimación extraordinaria no es usual, y por lo general ha sido utilizada a efectos de maximizar la tutela de derechos patrimoniales.

Así, por ejemplo, el caso típico de privación de legitimación de un derecho individual lo constituye el supuesto de sujeto intervenido en un proceso concursal. En este caso, lo usual es que se prive al titular del derecho iniciar cualquier tipo de acción relacionada a la defensa de sus derechos patrimoniales, y que la defensa de los mismos recaiga sobre otras personas.

En estos casos de privación de legitimación, se impone una restricción casi absoluta del derecho al acceso a la jurisdicción al sujeto que debería afirmar la titularidad del derecho, por lo cual es muy raro que se regule; y cuando ello ocurre, debe implicar una adecuada proporcionalidad entre los derechos y principios en juego. 
A diferencia de los casos de limitación de legitimación en defensa de derechos individuales, los casos en los cuales se utiliza esta figura para ampliar la legitimación son más frecuentes; toda vez que no implican la restricción de derechos, ya que permiten que terceros puedan interponer pretensiones a favor de derechos de otras personas.

Así, el supuesto de ampliación de legitimación de derechos individuales lo constituye la "sustitución procesal", figura a través de la cual se permite que un tercero interponga pretensiones sobre derechos que afirma son de titularidad ajena. Esta figura tiene su sustento en la protección de derechos patrimoniales de un determinado sujeto, el cual por su acción - u omisión -, puede originar un deterioro del mismo, en perjuicio de sus acreedores.

En ese sentido, para la configuración de los casos de sustitución procesal se requerirá de la existencia de dos relaciones jurídicas materiales distintas, que si bien no tienen elementos objetivos comunes, sí comparten un elemento subjetivo común. La primera relación jurídica material debe ser entre un acreedor y un deudor. La segunda relación jurídica material debe ser entre el acreedor mencionado (que en esta nueva relación sería un deudor) y un acreedor del mismo. Mediante la figura de la sustitución procesal se permite que el acreedor de la segunda relación material inicie un proceso a nombre del acreedor de la primera relación material contra el deudor de este.

En estos casos, al no existir un traspaso del derecho material de una persona a favor de otra, nos encontramos ante un supuesto de legitimación extraordinaria. Señala Montero Aroca $(2007,337)$ : "La sustitución procesal se resuelve de esa manera en un fenómeno puramente procesal en virtud del cual quien es titular activo de la primera relación jurídica (A) ejercita el derecho del titular de la segunda relación (B) como medio para impedir que su relación se vea perjudicada, no jurídicamente, pero sí de hecho por la inactividad de este segundo, y así interpone la acción (= derecho) de éste contra C. Con ello no se concede nada material al luego sustituido (A), sino algo meramente procesal, dado que el otorgamiento de la legitimación no le modifica, en cualquiera de los sentidos imaginables, su derecho material. Puede hacerlo efectivo de hecho, pero no se altera jurídicamente".

El caso típico de la sustitución procesal lo constituye la acción subrogatoria, figura regulada en el Código Civil. Dicha acción permite a un acreedor interponer pretensiones a favor de su deudor a efectos de tutelar los derechos de este, sin necesitar autorización previa alguna.

Finalmente, conviene señalar que la sustitución procesal en ningún momento genera un derecho a favor de la persona que inicia el proceso. Esta persona no inicia un proceso solicitando tutela a su favor, sino en favor de los derechos de una tercera persona. En ese sentido, la cosa juzgada se configura de manera normal en su ámbito objetivo y subjetivo; es decir, se circunscribe a resolver la controversia sobre la relación jurídico material en juego, y sólo involucra a las partes sobre las cuales debe recaer la titularidad del derecho y la imputación de la obligación.

5.2.2. La legitimación extraordinaria de derechos o intereses supraindividuales

Los derechos colectivos son aquellos cuya titularidad no pueden referirse a un número determinado de personas, sino al conjunto de ellas consideradas como un grupo. En ese sentido, se ha definido que esta clase de derechos obedecen a intereses supraindividuales, entendidos estos como "el interés legítimo compartido por una categoría o conjunto de sujetos que se encuentren en igual o similar posición con relación a un bien del que todos ellos disfrutan simultáneamente o conjuntamente, de forma concurrente y no exclusiva, respecto del cual experimenta una común necesidad" (Gutierrez de Cabiedes 2001, 142).

Esta clase de derechos o intereses supraindividuales se clasifican a su vez en: (i) intereses individuales homogéneos, (ii) derechos colectivos; y, (iii) derechos difusos. Los mismos han sido definidos por la doctrina (Glave 2013, 503) de la siguiente manera:

- Derechos difusos: cuya caracterización está referida a un número indeterminado 


\section{Rafael Prado Bringas Orestes Francisco Zegarra Valencia}

e indeterminable de titulares, a la naturaleza indivisible e indisponible del bien jurídico afectado y la conexión fáctica generada por el daño materia de la pretensión colectiva. Los ejemplos más claros se encuentran en casos relacionados a daños al medio ambiente o derecho de los consumidores.

- Derechos colectivos: son los que pertenecen a un número indeterminado, pero determinable de titulares, entre los que existe una relación jurídica base que los vincula entre sí o con la parte contraria. Los miembros de la colectividad pueden ser identificables, precisamente por la existencia de esta relación jurídica previa entre ellos mismos o con la contraparte.

- Intereses individuales homogéneos: Hacen referencia a derechos subjetivos ontológicamente individuales y a la divisibilidad del bien jurídico entre la comunidad de afectados, pero se tratan colectivamente porque tienen por origen común la conducta de la parte contraria. Entonces la homogeneidad está definida por dicho origen común.

Lo característico de esta clase de derechos es que siendo comunes a varias personas no llegan a perder la individualidad de su titularidad; y esta característica en particular es la que origina que se encuentren en una situación jurídica única. De esta manera, al encontrarnos ante una clase particular de derechos cuya titularidad se encuentra en el limbo entre lo individual y colectivo; es que su tutela en el proceso debe ser conferida a una determinada persona, la misma que interpondrá una pretensión sin poder afirmar la titularidad del derecho.

De lo anterior es que se desprende la razón por la cual se habla de legitimación extraordinaria en los casos de derechos o intereses supraindividuales. $Y$ ello es porque se requiere de una norma procesal que establezca quienes son los legitimados para interponer pretensiones sobre esta clase de derechos. Señala Montero Aroca: "Es obvio que una cosa es la atribución de legitimación y otra la titularidad de los intereses; también puede decirse que la protección que se realice del interés de la colectividad no puede dejar de ser protección de interés de cada una de las personas. Incluso en sentido contrario, la protección que se haga del interés individual no puede dejar de afectar la tutela de todos los que se encuentran en la misma posición" (Montero 2007, 411).
Finalmente, conviene señalar que, si bien es cierto que el legislador tiene la facultad de establecer discrecionalmente quienes son las personas legitimadas para interponer pretensiones referidas a derechos supraindividuales; esta discrecionalidad debe tomar en cuenta diversos factores que permitan maximizar la tutela de estos derechos. Inclusive, y como ocurre en otros ordenamientos procesales, el legislador podría condicionar la legitimación de determinadas personas al cumplimiento de determinados requisitos; lo cual sería perfectamente válido puesto que, de ser proporcional y razonable, se haría para efectivizar la tutela de esta clase de derecho. Así, por ejemplo, en los Estados Unidos se requiere la certificación de demandas sobre derechos individuales homogéneos (class action); lo cual está regulado en el artículo 23 de las Federal Rules of Civil Procedure.

En ese sentido, compartimos la opinión de Mario Reggiardo cuando afirma sobre las class actions (opinión que puede extrapolarse a toda clase de procesos de derechos o intereses supraindividuales) que "la legitimad para demandar por class action tiene que estar limitada a las organizaciones sin fines de lucro que cumplan algunos de los requisitos controlados por el juez antes de la certificación. Una prestigiosa y respetada organización no lucrativa que tenga el derecho a entablar una class action es considerada una herramienta para reducir las demandas sin mérito, los problemas de agencia y transacciones desfavorables para los demandantes" (Reggiardo 2013, 478).

5.2.3. La legitimación extraordinaria de intereses públicos

Los intereses públicos son aquellos que afectan "más que a cada una de las personas que integran a la comunidad, a la comunidad misma, al conjunto de esas personas, independientemente del número de personas 
que la integren, debiendo añadirse que ese interés no es fraccionable, en el sentido de que no puede llegar a contemplar situaciones individualizadas" (Montero 2007, 439).

La defensa de esta clase de intereses se encuentra encomendada constitucionalmente al Ministerio Público (artículo 159 de la Constitución), entidad que cuenta, entre otras, con las siguientes atribuciones: (i) Promover de oficio, o a petición de pate, la acción judicial en defensa de la legalidad y de los interés públicos tutelados por el derecho (inciso 1 del artículo 159 de la Constitución); (ii) Representar en los procesos judiciales a la sociedad (inciso 3 del artículo 159 de la Constitución), (iiii) Ejercitar la acción penal de oficio o a petición de parte (inciso 3 del artículo 139 de la Constitución); y, (iv) Emitir dictamen previo a las resoluciones judiciales en los casos en los que la ley contempla (inciso 6 del artículo 139 de la Constitución).

En síntesis, el Ministerio Público es el garante constitucional de la legalidad e interviene en los procesos que establezca la ley, de acuerdo al rol que le atribuya esta. En esa línea, Marcial Rubio $(1999,259)$ señala que el Ministerio Público es "un órgano constitucional que vela por la legalidad de la vida política y social del país investigando, ejercitando acciones, e ilustrando las decisiones judiciales cuando ello le es requerido, en aplicación de la ley. La función y responsabilidad máxima del Ministerio Público es que la ley sea aplicada en todos los planos y niveles de la vida política y social. Desde luego, no tiene facultades coactivas ni la decisión directa para lograr, pero sí debe prestar la vigilancia a la vida social y ejercitar sus funciones en todo ámbito donde la ley sea incumplida".

En el caso del proceso civil la intervención del Ministerio Público es limitada, debido a que en esta clase de procesos no se resuelven controversias referidas al interés público; cuestión contraria a lo que sucede en el proceso penal. En ese sentido, su actuación en procesos civiles - y el grado de intensidad de la misma - dependerá de la discrecionalidad del legislador; lo que a su vez depende del grado de publicización del derecho civil.

Así, por ejemplo, en el proceso civil peruano se establece que en determinadas pretensiones relacionadas a familia o al interés superior del niño, que el Ministerio Público pueda iniciar procesos sin afirmar la titularidad de los derechos o intereses invocados; o que el Ministerio Público debe de ser emplazado como demandado. Además, y al margen de permitir su intervención de parte en el proceso, el legislador puede regular su intervención como dictaminador; a efectos que emita una opinión con relación a la controversia.

Finalmente, cabe señalar que en los casos en los que el Ministerio Público actué como demandado o como dictaminador de la controversia, su rol no se ve limitado a oponerse a la demanda, sino que este dependerá de lo que sea más beneficioso a la legalidad e interés público del caso concreto. Así, "en todos los casos en que el Ministerio Público no es demandante adoptará la posición formal de demandado, pero esto no quiere decir que tenga que oponerse necesariamente a la estimación de la pretensión del actor. Una cosa es su posición formal y otra que la defensa de la legalidad lo lleve a sostener lo que estime más adecuado a esa legalidad, incluida la estimación de la demanda" (Montero 2007, 446).

\section{Control de la legitimación en el proceso}

Cuando nos referimos al control de la legitimación implica abordar el control de la validez de la relación jurídica procesal. En ese sentido, dividiremos el presente acápite en tres partes: (i) en primer lugar explicaremos la importancia del principio de preclusión procesal y del saneamiento del proceso, (ii) luego explicaremos los alcances del control de la validez de la relación jurídica procesal en cada momento en que pueda ocurrir durante el proceso y, (iii) finalmente explicaremos cómo es que debe ser el análisis de la legitimación en el proceso.

\subsection{El principio de preclusión procesal y el saneamiento del proceso \\ El proceso civil ha sido definido por el maestro uruguayo como una "relación jurídica que constituye una secuencia o serie de actos que}




\section{Rafael Prado Bringas Orestes Francisco Zegarra Valencia}

se desenvuelven progresivamente, con el objeto de resolver, mediante un juicio de autoridad, el conflicto sometido a su decisión" (Couture 1981, 122). De esta manera, para que el proceso pueda lograr su conclusión natural (sentencia) se requiere que el mismo avance, y que cada fase pueda ser superada sin que deba existir la posibilidad de que las partes o el juez puedan retroceder a fases superadas. Para tales efectos, ha sido regulado el principio de preclusión procesal.

La palabra preclusión viene del verbo latino preludere, que significa "cerrar, atrancar, taponar, impedir", y el mismo es definido en el proceso como "la pérdida, extinción, consumación de una facultad procesal, que es posible reconocerla en tres situaciones diferentes: a) por no haberse observado el orden u oportunidad dado por la ley para la realización de un acto; b) por haberse cumplido una actividad incompatible con el ejercicio de otra; c) por haberse ejercitado ya una vez, válidamente, dicha facultad (consumación propiamente dicha)" (Eguren 2011, 454).

Ahora bien, una de las etapas del proceso en la cual el uso del principio de preclusión resulta idóneo es la del saneamiento, en la que el Juez verifica la validez de la relación jurídica procesal; es decir, si se cumple con los presupuestos que permiten al juez pronunciarse sobre el fondo de la controversia. En esa línea, conviene citar a Oscar Von Bülow cuando señala: "El tribunal no sólo debe decidir sobre la existencia de la pretensión jurídica en pleito, sino que, para poder hacerlo, también debe cerciorarse si concurren las condiciones de existencia del proceso mismo; además del supuesto de hecho de la relación jurídica privada litigiosa, tiene que comprobar si se da el supuesto de hecho de la relación jurídica procesal. Este dualismo ha sido siempre decisivo en la clasificación del procedimiento judicial. Él ha llevado a una división del proceso en dos capítulos, de los cuales uno se dedica a la investigación de la relación litigiosa material y el otro, al examen de los presupuestos procesales" (Von Bülow 1869, 28).

El saneamiento procesal puede utilizarse de dos maneras: "1) unas veces se tratará de terminar el proceso, impidiendo su entera tramitación, cuando se sabe que no puede conducir a una sentencia de fondo, y 2) otras veces se tratará de subsanar las cuestiones procesales para que, siguiéndose la tramitación del proceso, no exista ya la posibilidad de una sentencia meramente procesal o de absolución en la instancia" (Montero 2007, 517).
Conforme a lo anterior, se puede inferir que el saneamiento procesal esta intrínsecamente vinculado con el principio de preclusión, toda vez que permite concluir la controversia con relación a las cuestiones procesales y continuar con el proceso. En ese sentido, siguiendo lo señalado por Jordi Nieva Fenoll, "estas resoluciones tratan cuestiones incidentales, y podría predicarse tranquilamente de ellas sus efectos de cosa juzgada, teniendo en cuenta que concurre en las mismas el doble requisito de enjuiciamiento y de la necesidad de estabilidad, por supuesto limitando dichos efectos a su ámbito" (Nieva 2006, 134).

No podemos negar que el principio de preclusión ha sido criticado por ser demasiado rígido. Es cierto. La inclusión de este principio impide que se renueven actos procesales consumados, o que se extiendan los plazos a situaciones vencidas. No compartimos las críticas a su rigidez porque precisamente de eso trata la preclusión, impedir que el proceso retroceda por actos que las partes o el juez debieron hacerse cargo; sin embargo, la solución no es eliminar la preclusión, sino de saber en qué momento del iter procesal va a aparecer y, en casos excepcionales, darle al juzgador la oportunidad para derrotar las normas preclusivas.

\subsection{Análisis y delimitación del control de la validez de la relación jurídica procesal durante el proceso}

En el proceso civil peruano, el legislador ha optado porque el juez realice el saneamiento del proceso en la etapa postulatoria. Sobre el particular, Juan Monroy Gálvez señala: "Este nuevo objetivo de la postulación, le impone al juez el deber de revisar el cumplimiento por parte del demandante de los requisitos de admisibilidad y procedencia de la demanda, concediéndole, en contraprestación, la facultad de devolverla y darle un plazo al pretensor para que la subsane o rechazar la demanda, cuando así lo considere pertinente 
(...) la otra posibilidad es que el demandado plantee excepciones otras defensas procesales. En este caso, el juez debe tramitarlas y, al final, resolverlas. De igual manera, si no ampara las excepciones o las otras defensas procesales, deberá, luego de analizar otros aspectos del procedimiento, declararlo saneado" (Monroy 2017, 90).

El juez puede sanear el proceso hasta en dos oportunidades en la etapa postulatoria: (i) cuando se pronuncia sobre el control liminar de la demanda, y (ii) en el momento específico del saneamiento procesal.

Sobre el control liminar de la demanda, la doctrina nacional ha señalado que "es la atribución que le confiere el ordenamiento jurídico al Juez para evaluar si la demanda cumple con determinados requisitos, antes que sea puesto en conocimiento del demandado; de modo que si no los cumple, el juez dispone el inmediato rechazo de la demanda" (Priori y Ariano 2009, 104). Esta atribución tiene fundamento constitucional, ya que reside en el derecho a la tutela jurisdiccional efectiva, pues "supone una grave afectación la a tutela jurisdiccional efectiva el tener que transitar por todo el proceso y, recién al término de él, encontrar una resolución que advierta la ausencia de un presupuesto procesal que pudo ser advertido desde su inicio por el Juzgador".

De esta manera, mediante el control liminar de la demanda el juez puede analizar la validez de la relación jurídica procesal, a través de las causales de improcedencia establecida el código procesal civil. Así, en caso considere que la demanda se encuentra inmersa en una de dichas causales, declarara in limine la improcedencia de la demanda.

Ahora, en cuanto a la etapa de saneamiento, el juez analiza la relación jurídica procesal tomando en cuenta las excepciones y las casuales de improcedencia planteadas por el demandado. Como resultado de este análisis, el juez podrá: 1) declarar la existencia de una relación jurídica procesal válida y continuar con el proceso 2) declarar la nulidad de todo lo actuado y concluir el proceso por constatar un vicio de carácter insubsanable; o, 3) conceder un plazo para que se subsanen los vicios pasibles de serlo.

Finalmente, conviene señalar que el legislador ha optado por establecer una tercera oportunidad para que el juez pueda analizar la validez de la relación jurídica procesal, y esta es al momento de emitir sentencia. En relación a ello, la doctrina nacional ha señalado que: "nuestro código procesal civil faculta al juez a emitir sentencias inhibitorias, pronunciándose sobre los defectos de la relación procesal, pero no para regularizarla o sanearla, sino para concluir el proceso, con una decisión inhibitoria, ocasionada justamente por la invalidez de tal relación, que impide un pronunciamiento de fondo. Esta actividad se vincula al saneamiento (negativo en este supuesto) con la sentencia (cuando es inhibitoria)" (Hurtado Reyes 2014, 795). A resumidas cuentas, mediante la sentencia inhibitoria el juez podrá nuevamente pronunciarse sobre las causales de improcedencia establecidas en el Código Procesal Civil.

De lo expuesto se evidencia que el saneamiento puede realizarse hasta en tres ocasiones en el proceso civil y ello a nuestro juicio, puede desnaturalizar el propósito del principio de preclusión y del saneamiento. En palabras de Eugenia Ariano: "La preclusión de la deducción de cuestiones (automáticamente) procesales sólo tiene sentido si de ello se hace descender una consecuencia útil para el proceso" (Ariano 2013, 89).

A lo anterior, debemos agregar que mediante las causales de improcedencia y las excepciones se pueden denunciar los mismos defectos de la relación jurídica procesal. Así, por ejemplo, la falta de legitimación de una de las partes puede plantearse como causal de improcedencia o excepción. Si es invocada como causal de improcedencia, puede interponerse hasta en tres ocasiones durante la primera instancia.

En ese sentido, a efectos de velar por un proceso coherente y respetuoso del derecho a la tutela jurisdiccional efectiva, el análisis que debe realizar el juez a través del control liminar de la demanda y al momento de emitir sentencias debe ser excepcional y limitado a situaciones 


\section{Rafael Prado Bringas Orestes Francisco Zegarra Valencia}

concretas. A su vez, la etapa del saneamiento procesal propiamente dicha se presenta como el momento idóneo para analizar - y precluir - el control de la relación jurídico procesal.

El inconveniente del control liminar de la demanda es que juez analiza la relación jurídica procesal con información incompleta, ya que aún no ha tenido oportunidad de escuchar al demandado; y debido a ello, no se encuentra en el escenario óptimo para emitir un pronunciamiento. En relación a ello, en una opinión que puede ser aplicada a cuestiones procesales, Robet Cooter y Thomas Ulen señalan que: "Los tribunales tienen información imperfecta, lo que los lleva a cometer errores cuando aplican el derecho sustantivo. Pero a medida que mejora la información, los tribunales comenten menos errores". A lo anterior, debemos agregar que este análisis no es definitivo, lo cual le resta eficiencia (Cooter y Ulen 2008, 570).

Tomando en consideración lo expuesto, el análisis de la relación jurídica procesal mediante el control liminar de la demanda debe de limitarse a impedir la continuación de demandas en las cuales las causales de improcedencia sean manifiestas. Sobre el particular, señala Giovanni Priori que: "En estos casos, lo que se le exige al juez es que interprete estas normas en el sentido más favorable a la protección de los derechos fundamentales (pro homine) y que, en caso de duda, dé trámite a la demanda. No hacerlo, en caso de duda, supondría una mayor lesión al derecho de acceso a la justicia, antes que la protección o el beneficio a los otros derechos que con dicha facultad se desea proteger. La función del juez en estos casos es fundamental, en la medida que tiene que establecer como se afectan o protegen los distintos valores constitucionales en juego en el caso concreto" (Priori 2009, 113).

Ahora, con respecto al inconveniente de analizar la relación jurídica procesal al momento de emitir sentencia, es que el juez se pronunciará sobre cuestiones que, en principio, ya deberían estar superadas y cuyo análisis debería de estar precluido. En ese sentido, dicho análisis puede afectar el principio de seguridad jurídica y el derecho a la tutela jurisdiccional efectiva, ya que una vez superada la etapa del saneamiento el demandante tiene la expectativa legitima de que se emitirá una sentencia sobre el fondo de la controversia; hecho que se podría agravar si se advierte la improcedencia de oficio sin permitir que las partes se pronuncien sobre la misma, o es declarada en segunda instancia o en sede casatoria. Sobre el particular, conviene citar una sentencia emitida por el Tribunal Constitucional en un proceso de amparo contra resolución judicial, mediante la cual se señaló que se vulnera el principio de congruencia procesal cuando el juez, al resolver un recurso de apelación, no se pronuncia sobre los agravios que contiene, sino que rechaza la demanda por improcedente a pesar de que la etapa de calificación de la demanda ha concluido y se desestimaron los cuestionamientos a la relación jurídica procesal planteados por el demandado.

Así, en la STC 2605-2014-PA el máximo intérprete de la constitución ha señalado: "Los demandados (...) dedujeron las excepciones de incompetencia, cosa juzgada, oscuridad y ambigüedad de la demanda, caducidad y defensas previas, y todas ellas fueron desestimadas en primer y segundo grado, entonces correspondía a la Sala Civil emitir un pronunciamiento sobre el fondo del asunto (como sí lo hizo el órgano judicial de primer grado), y no uno inhibitorio, puesto que la etapa de calificación de la demanda ya había precluido y el proceso se encontraba saneado. (...) Para este Tribunal, la citada resolución casatoria contiene vicios de inconstitucionalidad, no porque ella se haya señalado un hecho falso, asunto que carece de objeto analizarlo en autos; sino porque al declarar improcedente el recurso de casación del recurrente no tuteló los agravios que éste expuso respecto de la resolución de vista (...)" (STC 2605-2014-PA).

En ese contexto, el análisis de la validez de la relación jurídica procesal al momento de emitir sentencia debe ser excepcional, y a efectos de no atentar contra el principio de preclusión procesal y los derechos de las partes, este debe de limitarse al control de hechos nuevos, distintos a los analizados en la etapa del saneamiento procesal. En ese sentido, suscribimos la opinión de Eugenia Ariano, quien sobre el particular ha señalado que: "Sería bueno tomar adecuada nota de que cuando el juez emite la resolución de 'saneamiento 'ex inc. 1 del artículo 465 CPC, 
agota su poder de pronunciarse (nuevamente) sobre lo mismo, por lo que, una vez llegado 'el momento' de la sentencia, no le queda, como regla, sino emitir un pronunciamiento de fondo, estimatorio o desestimatorio de la demanda. Sostener lo contrario es palmariamente contrario a lo dispuesto en el artículo 406 CPC. Pero si esta es la 'regla', ¿Cuál sería la 'excepción'? Vale decir, ¿Cuáles serían los supuestos de excepción que hacen legítima una sentencia de absolución de instancia? Si se tiene presente que el juez (de compartirse los alcances dados al artículo $406 \mathrm{CPC}$ ), está impedido de pronunciarse, en sentido incompatible, dos (o más) veces sobre lo mismo, la respuesta debería sobrevenir sola: cuando no se haya previamente pronunciado, que es como decir que el supuesto para emitir la sentencia meramente absolutoria de instancia debe ser 'nuevo', entendiéndose por 'nuevo' no necesariamente un hecho sobrevenido a la emisión del auto de saneamiento ex inc. 1 del artículo el mismo autor 465 CPC, sino también que lo sobrevenido sea su conocimiento" (Ariano 2013, 98).

Con relación a la emisión del auto de saneamiento, este es el momento idóneo para sanear el proceso, debido a que el juez analiza la relación jurídica procesal teniendo toda la información posible, ya que el demandado se ha apersonado al proceso y ejercido su derecho de defensa (y con ello planteado las causales de improcedencia o excepciones que considere pertinentes). Además, este momento permite que el juez pueda dar por superadas las cuestiones procesales, enfocarse en las pruebas del proceso y demás cuestiones pertinentes a efectos de emitir un pronunciamiento de fondo sobre la controversia.

De todo lo expuesto hasta el momento sobre el saneamiento del proceso y el control de la validez de la relación jurídica procesal podemos concluir lo siguiente: (i) el control liminar debe de limitarse a casos en los que sea manifiesta la existencia de una causal de improcedencia taxativamente establecida; (ii) la etapa del saneamiento procesal propiamente dicha es el momento idóneo donde el juez debe de analizar la validez de la relación jurídico procesal, en virtud a las causales de improcedencia o excepciones formuladas por el demandado; y, (iii) la emisión de sentencias inhibitorias por invalidez de la relación jurídico procesal debe estar limitada al control de hechos sobrevinientes al saneamiento del proceso.

\subsection{Control de la legitimación durante el proceso}

En ese sentido, y aterrizando al control de la legitimación en las tres etapas que hemos identificado anteriormente, podemos afirmar que el control liminar de la demanda debe limitarse a los casos en los que sea manifiesta la falta de legitimación del demandante o del demandado; $y$, caso de cualquier duda sobre la legitimación de las partes, o de la acreditación de la misma, el juez no puede declarar improcedente in limine la demanda, sino que debe admitirla y darle trámite.

Ahora, con relación al control de la legitimación en el momento de emitir sentencia, este debe de limitarse a hechos que no han sido objeto de control en la etapa de saneamiento procesal; lo cual, a nuestro juicio, sólo podrá ocurrir cuando se incorpore alguna parte al proceso de manera posterior a la etapa de saneamiento; o en el supuesto - casi - negado de que un tercero denuncie la existencia de un litisconsorcio necesario pasivo que por alguna razón paso inadvertido en el proceso, ya que para todos los demás casos ya debería haber realizado el juez el análisis de si las partes tienen o no legitimación.

Finalmente, el control de la legitimación en la etapa de saneamiento procesal se da conforme a las excepciones planteadas por el demandado y originará las consecuencias establecidas por la norma procesal. Así, en caso el juez declare fundada la excepción de falta de legitimidad para obrar pasiva, deberá suspender el proceso hasta que se establezca la relación jurídico procesal con los sujetos que correspondan; mientras que, si declara fundada la excepción de falta de legitimidad para obrar activa, deberá anular todo lo actuado y dar por concluido el proceso.

\section{Conclusión}

La legitimación, como presupuesto procesal, constituye un elemento que debe limitarse a analizar quienes pueden iniciar un proceso en base a los derechos invocados. Como hemos visto, la regla general constituye que tendrá legitimidad para obrar activa la 
Rafael Prado Bringas

Orestes Francisco Zegarra Valencia

persona que afirme la titularidad del derecho invocado, y tendrá la legitimidad para obrar pasiva la persona sobre la que se considere recae la obligación imputada; sin embargo, también hemos visto que esta regla se ha visto enriquecida - $y$ hasta superada - por las exigencias del derecho material.

\section{Referencias bibliográficas}

Ariano Deho, Eugenia. 2013. Hacia un proceso civil flexible: crítica a las rec/usiones rígidas del Código Procesal Civil peruano de 1993. Lima: Ara Editories.

Calamandrei, Piero. 1989. Instituciones del derecho procesal civil. Buenos Aires: Ediciones Jurídicias Europa-América.

Cooter, Robert, y Ullen, Thomas. 2008. Derecho y Economía. México Distrito Federal: Fondo de Cultura Económica.

Couture, Eduardo. 1981. Fundamentos del Derecho Procesal Civil. Buenos Aires: Depalma.

Eguren, María Carolina. 2011. El principio de eventualidad procesal. Santa Fe: Rubinzal Culzoni.

Glave, Carlos. 2013. La ausencia de un modelo de tutela de derechos colectivos. En Las garantias del justo proceso. Ponencias del Tercer Seminario Internacional Proceso y Constitución. Lima: Palestra.

Gutierrez de Cabiedes, Pablo. 2001. En Comentarios a la Ley de Enjuiciamiento Civil I. Pamplona: Aranzadi.

Hurtado Reyes, Martín. 2014. Estudios de Derecho Procesal Civil. Lima: Idemsa.

Marinoni, Luiz. 2007. Derecho fundamental al a tutela jurisdiccional efectiva. Lima: Palestra.
Matheus, Carlos. 2001. Parte, tercero, acumulación e intervención procesal. Lima: Palestra.

Monroy, Juan. 1994. Las excepciones en el Código Procesal Civil peruano. Themis, 119-129.

Monroy, Juan. 1995. La representación técnica o judicial del abogado y el recurso de apelación. IUS ET VERITAS, 276.

Monroy, Juan. 2017. La postulación del proceso, hoy. En Biblioteca de Derecho Procesal. Lima: Communitas.

Montero, Juan. 2007. De la legitimación en el Proceso Civil. Barcelona: Bosch.

Nieva Fenoll, Jordi. 2006. La cosa juzgada. Barcelona: Atelier.

Nieva Fenoll, Jordi. 2015. Derecho Procesal II. Proceso Civil. Madrid: Marcial Pons.

Pallares, Eduardo. 1979. Derecho Procesal Civil. México Distrito Federal: Porrúa.

Priori, Giovanni. 2010. Comentarios al artículo VI del Título Preliminar del Código Civil. En Código Civil Comentado. Lima: Gaceta Jurídica.

Priori, Giovanni y Ariano, Eugenia. 2009. ¿Rechazando la injusticia? El derecho de acceso a la justicia y el rechazo liminar de la demanda. Themis.

Proceso de Inconstitucionalidad, 005 (Tribunal Constitucional 2006).

Reggiardo, Mario. 2013. Los problemas de la class action y su aplicación en Perú. En Proceso y Constitución: Las garantías del justo proceso. Lima: Palestra.

Rubio, Marcial. 1999. Estudio de la Constitución Política de 1993. Lima: Fondo Editorial de la Pontificia Universidad Católica del Perú.

Von Bülow, Oskar. 1869. Die lehre von dem processeinreden un die processvoraussetzungen. (M. Rosas Lichtschein, Trad.) Giesen: Emil Roth. 


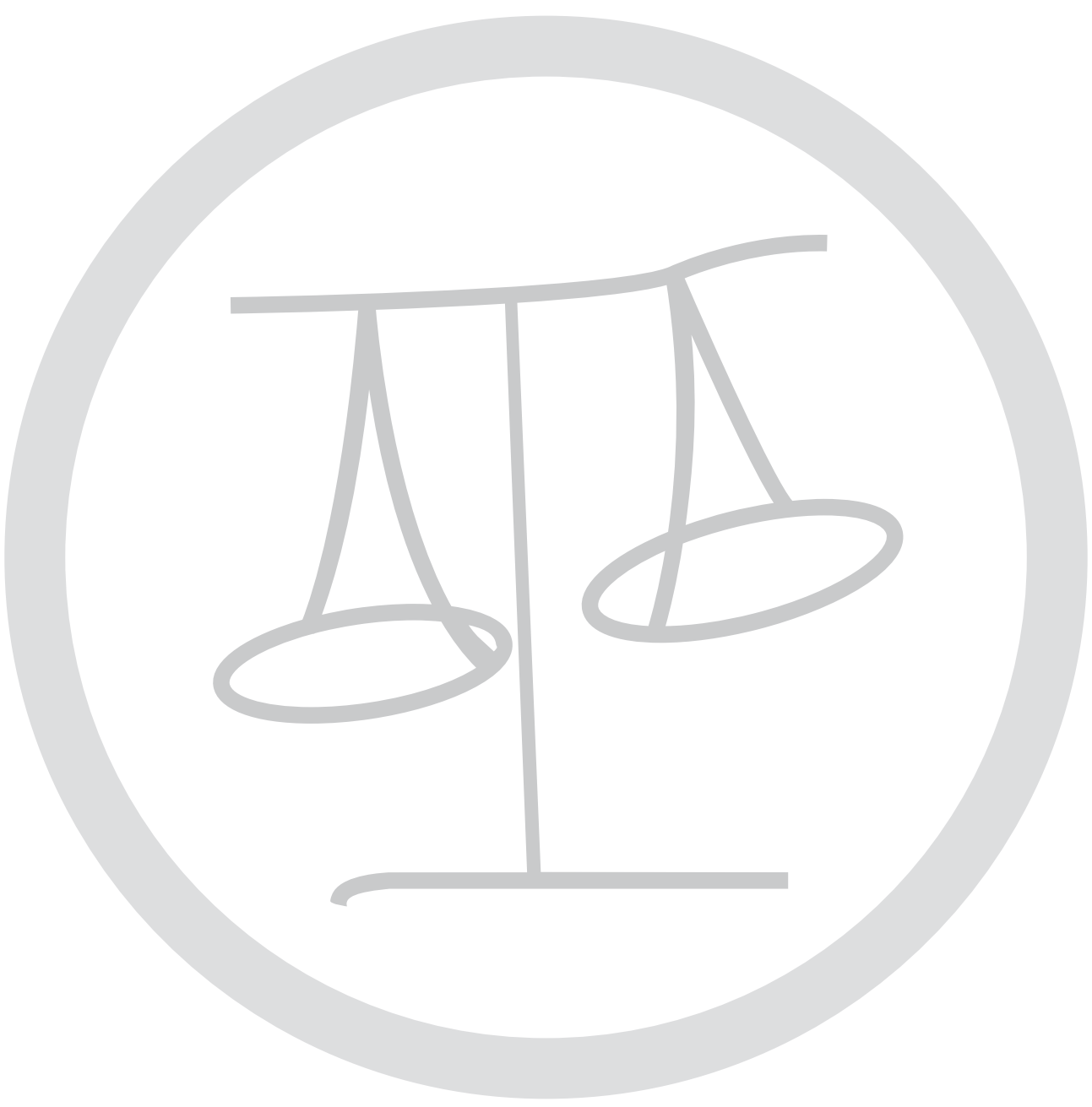

